\title{
An ultra-low magnetic field thermal demagnetizer for high-precision paleomagnetism
}

\author{
Huafeng Qin ${ }^{1 *} \mathbb{D}$, Xiang Zhao ${ }^{1,2}$, Shuangchi Liu' ${ }^{1}$, Greig A. Paterson ${ }^{3,4}$, Zhaoxia Jiang ${ }^{1,5}$, Shuhui Cai ${ }^{1}$, Jinhua Li ${ }^{3}$, \\ Qingsong Liu ${ }^{1,6}$ and Rixiang Zhu ${ }^{1}$
}

\begin{abstract}
Thermal demagnetization furnaces are widely used paleomagnetic facilities for progressive removal of naturally acquired magnetic remanence or the imparting of well-controlled laboratory magnetization. An ideal thermal demagnetizer should maintain "zero" magnetic field in the sample chamber during thermal treatments. However, magnetic field noises, including the residual magnetic fields of the construction material and the induced fields caused by the alternating current (AC) in the heating element are always present, which can contaminate the paleomagnetic results at the elevated temperatures or especially for the magnetically weak samples. Here, we designed a new structure of heating wire named "straight core solenoid" to develop a new demagnetization furnace with ultralow magnetic field noise. Simulation and practical measurements show that the heating current magnetic field can be greatly reduced by using the new technology. Thermal demagnetization experiments demonstrate that the new demagnetizer can yield low noise results even for weakly magnetic samples.
\end{abstract}

Keywords: Paleomagnetism, Thermal demagnetization, Furnace, AC magnetic field, Residual magnetic field, Heating wire structure, Straight core solenoid

\section{Introduction}

Paleomagnetism investigates changes in the geomagnetic field through geologic time by the measurement of natural remanent magnetizations (NRM) recorded by magnetic minerals in natural materials. NRM of geological materials usually consists of multiple components. Therefore, to define the stable characteristic remanent magnetization (ChRM) of geological interests, the secondary remanent magnetization needs be removed using sequential demagnetization techniques (e.g., the stepwise progressive thermal or alternating field demagnetization) (Irving et al. 1961; Schmidt 1993). During thermal demagnetization, specimens are heated to a pre-selected temperature, held for a period of time (e.g., 10-30 min),

\footnotetext{
*Correspondence: huafeng_qin@mail.iggcas.ac.cn

1 State Key Laboratory of Lithospheric Evolution, Institute of Geology and Geophysics, Chinese Academy of Sciences, Beijing 100029, China Full list of author information is available at the end of the article
}

and then cooled down to the room temperature in "zero" magnetic field environment (Collinson 1983). This treatment will be conducted repeatedly in a stepwise manner till the ChRM is isolated (Thellier 1966; Collinson 1975). Thermal demagnetization is one of the standard demagnetization methods, and thus thermal demagnetization furnaces (or thermal demagnetizers) have been widely equipped in nearly all paleomagnetic laboratories.

Although widely used, the experimental success rate of thermal demagnetization can be relatively low especially for weakly magnetic samples such as sedimentary rocks. It is often found that remanent direction of some specimens become seriously distorted at high temperatures, but the ChRM can still be obtained by alternating field demagnetization using sister specimens (e.g., Holm and Verosub 1988). The failure of thermal demagnetization could be attributed to irreversible thermal physiochemical alterations upon heating (e.g., Wasilewski 1969; 
Heller et al. 1970), partial thermoremanent magnetization (pTRM) acquisition in the presence of a residual DC field upon cooling (Collinson 1975), or magnetic fields caused by the heating current (Heller et al. 1970). Although early studies did not detect differences between inductive and non-inductive heating wire (Irving et al. 1961), inductive alternating fields (AF) can cause unwanted AF demagnetization behavior at high temperatures. Given that the coercivity of magnetic minerals reduces quickly as the temperature approaches the unblocking temperature or Curie temperature, this effect may be substantial. In the extreme, the NRM direction could be biased by single axis AF demagnetization because of the stationary current field (Stephenson 1983) at high temperature.

Reducing the residual fields in thermal demagnetizers can significantly improve the quality of paleomagnetic measurements, particularly for weakly magnetized specimens. Moreover, for the study of meteorites in planetary science or magnetizations acquired near the onset of the geodynamo, understanding the characteristic remanent magnetization acquired in low magnetic fields, including extremely weak fields (nT range) is a topic of great interest (Weiss et al. 2010; Tarduno et al. 2015; Wang et al. 2017). It is important that the technology around thermal demagnetizers progress to keep pace with the changing demands of the scientific community.

In this study, we will first describe the technology to reduce the residual magnetic field for a newly designed thermal demagnetizer. The key point is to reduce the current magnetic field by adopting a new structure of heating element. We then conduct thermal demagnetization experiments to test the performance of the new furnace.

\section{Newly designed furnace for thermal demagnetization}

The heating elements in thermal demagnetizers are typically constructed of non-inductive windings in order to minimize the AC demagnetization effect of the heating current (Chamalaun and Porath 1968). There are generally two types of non-inductive heater winding, one is a bifilar solenoid wrapped on a cylindrical form to heat specimens within (Fig. 1a). This style of winding is widely used in small furnaces such as the Sogo Fine-TD furnace in Japan (Zheng et al. 2010a, b). It is also used in some Kappabridges and

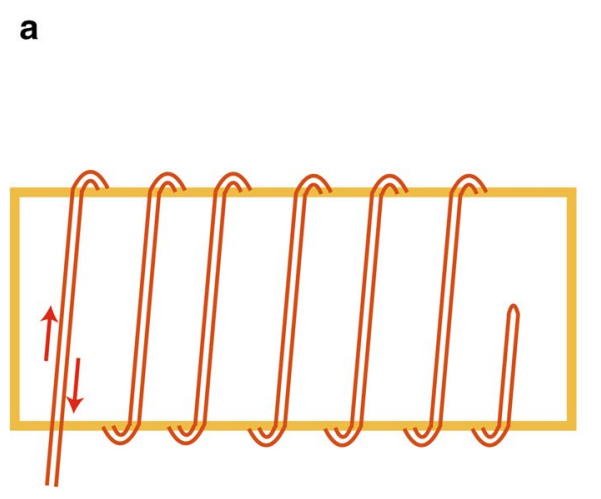

b
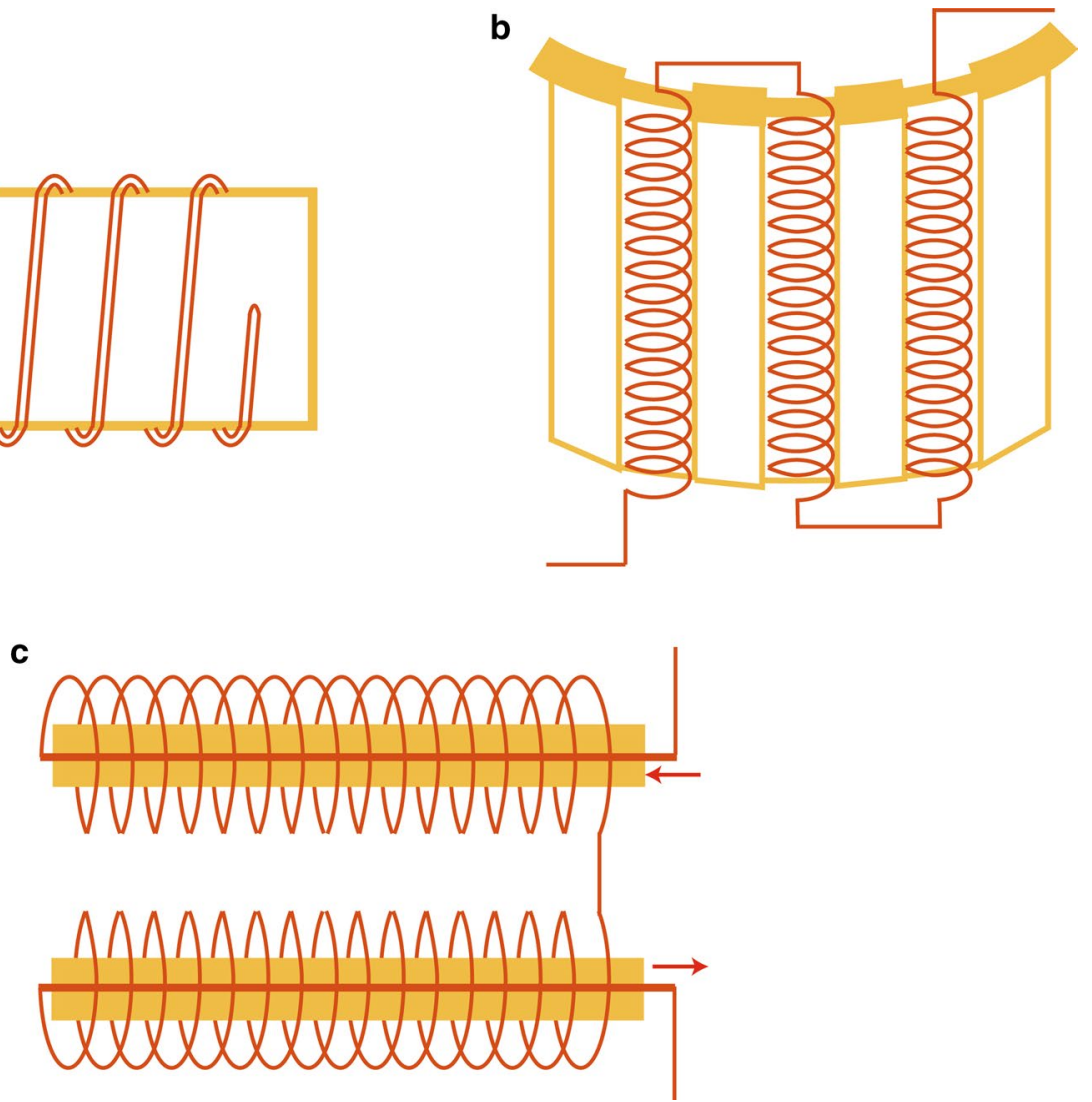

Fig. 1 Configuration of non-inductive heating wires. a Bifilar solenoid wrapped for a small oven, $\mathbf{b}$ solenoid-like helical heating wires arranged in a larger oven, $\mathbf{c}$ the new straight core solenoid heating wires using in the TD-PGL-100. Arrows indicate the current flow direction 
variable field translation balances (VFTBs) to heat specimens. In this configuration, the opposing currents of adjacent wires reduce the AC magnetic field. In addition, the wire spacing should be small enough to efficiently reduce the residual magnetic field. A disadvantage of this system, however, is that it will increase the risk of short circuit, and often lead to limited sample capacity in order to maintain an acceptable resistance and workable power consumption.

An alternative method is to use solenoids arranged in opposite direction (Fig. 1b) or wound into a helix as in many commercial furnaces. It is usually assumed that the magnetic field generated by a uniform solenoid is only in the interior and both ends of the solenoid, but this neglects the fact that for a real solenoid the wire loops (and current loops) are not perfectly circular, the current must go from one end to the other, which results in non-zero external fields. Therefore, it is necessary to consider the magnetic field distribution outside a helical solenoid.

\section{Simulated calculation of solenoid magnetic field}

The magnetic field distribution outside a solenoid can be calculated using the Biot-Savart law (Hagel et al. 1994; Budnik and Machczynski 2011). Assuming a current, I, flowing in a finite solenoid with a radius of $R$ and a pitch of $p$, the vectors of magnetic field at point $\mathrm{P}$ (Fig. 2) produce by a differential current element $I d l$ at source point $\mathrm{N}(X s$, $Y s, Z s)$ can be written as:

$$
d B=\frac{\mu_{0} I}{4 \pi} \frac{d \vec{l} \times \vec{r}}{r^{3}}
$$

where $r$ is distance from the point $\mathrm{N}$ on the filament to the field point P. $X s=R \cos \Theta, Y s=R \sin \Theta$ and $Z s=a \Theta$ since the point $\mathrm{N}$ is on the solenoid, where $a$ is the pitch factor.

From cylindrical coordinates to Cartesian coordinates, $d l$ and $r$ can be expressed as:

$$
\begin{aligned}
d \vec{l} & =\vec{i} d x+\vec{j} d y+\vec{k} \\
d z & =-\vec{i} R \sin \theta d \theta+\vec{j} R \cos \theta d \theta+\vec{k} a d \theta, \\
\vec{r} & =\vec{i}\left(x_{0}-R \cos \theta\right)+\vec{j}\left(y_{0}-R \sin \theta\right)+\vec{k}\left(z_{0}-a \theta\right) .
\end{aligned}
$$

Therefore:

$$
d \vec{l} \times \vec{r}=\left|\begin{array}{ccc}
\vec{i} & \vec{j} & \vec{k} \\
-R \sin \theta d \theta & R \cos \theta d \theta & a d \theta \\
x_{0}-R \cos \theta & y_{0}-R \sin \theta & z_{0}-a \theta
\end{array}\right|,
$$

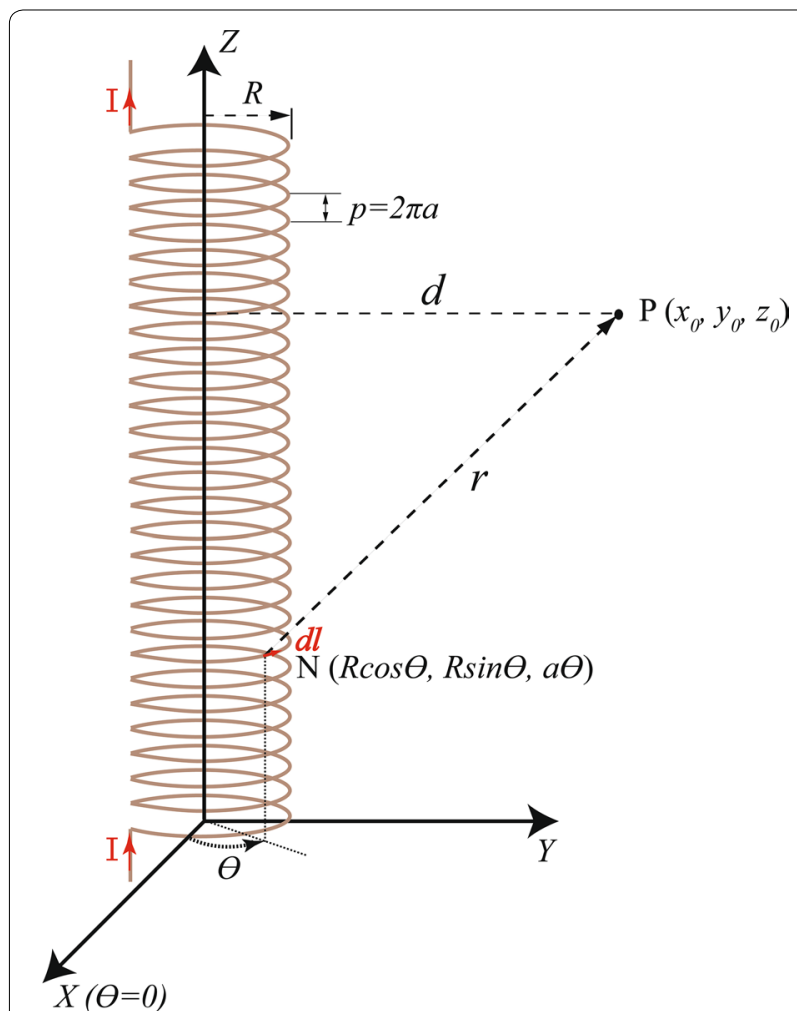

Fig. 2 Schematic diagram for calculating magnetic field outside of solenoid ( $\mathrm{R}$ is the radius of solenoid, $p=2 \pi a$ is the pitch distance and $d$ is the distance between point $P$ and central axis of solenoid)

$d B_{x}=\frac{\mu_{0} I}{4 \pi} \frac{\left[\left(z_{0}-a \theta\right) R \cos \theta-\left(y_{0}-R \sin \theta\right) a\right] d \theta}{\left[\left(x_{0}-R \cos \theta\right)^{2}+\left(y_{0}-R \sin \theta\right)^{2}+\left(z_{0}-a \theta\right)^{2}\right]^{3 / 2}}$,

$d B_{y}=\frac{\mu_{0} I}{4 \pi} \frac{\left[\left(z_{0}-a \theta\right) R \sin \theta+\left(x_{0}-R \cos \theta\right) a\right] d \theta}{\left[\left(x_{0}-R \cos \theta\right)^{2}+\left(y_{0}-R \sin \theta\right)^{2}+\left(z_{0}-a \theta\right)^{2}\right]^{3 / 2}}$,

$d B_{z}=-\frac{\mu_{0} I}{4 \pi} \frac{\left[\left(y_{0}-R \sin \theta\right) R \sin \theta+\left(x_{0}-R \cos \theta\right) R \cos \theta\right] d \theta}{\left[\left(x_{0}-R \cos \theta\right)^{2}+\left(y_{0}-R \sin \theta\right)^{2}+\left(z_{0}-a \theta\right)^{2}\right]^{3 / 2}}$.

As the radius of the solenoid decreases, or when the distance between the point $P$ and solenoid is much larger than the radius, $\mathrm{R}$ can be approximately ignored. The point $\mathrm{N}$ on a straight wire is $(0,0, a \theta)$, and filament became as $d \vec{l}=\vec{k} a d \theta$, and $\vec{r}=\vec{i} x_{0}+\vec{j} y_{0}+\vec{k}\left(z_{0}-a \theta\right)$, and therefore, the formula of magnetic field can be simplified as:

and we have 


$$
\begin{aligned}
& d B_{x}=-\frac{\mu_{0} I}{4 \pi} \frac{y_{0} a d \theta}{\left[x_{0}^{2}+y_{0}^{2}+\left(z_{0}-a \theta\right)^{2}\right]^{3 / 2}}, \\
& d B_{y}=\frac{\mu_{0} I}{4 \pi} \frac{x_{0} a d \theta}{\left[x_{0}^{2}+y_{0}^{2}+\left(z_{0}-a \theta\right)^{2}\right]^{3 / 2}}, \\
& d B_{z}=0 .
\end{aligned}
$$

It can be seen that when the solenoid diameter is small, the magnetic field generated by the solenoid is roughly the same as that of a straight wire. Therefore, to reduce the stray external fields of a solenoid, a straight wire can be inserted through its core and connected with solenoid at one end, such that the current in the straight wire is flowing opposite to the current in the solenoid (Fig. 1c). A new heating element is designed based on this configuration which we call it straight core solenoid, and will be used to manufacture our new thermal demagnetizer.

To simulate a heating element solenoid, we assume that the solenoid length is $1 \mathrm{~m}$, the radius is $4 \mathrm{~mm}$, and the pitch is also $4 \mathrm{~mm}$. And the current is set to $1 \mathrm{~A}$. We simulate the fields in $\mathrm{YZ}$ plane (Fig. 2) along the direction of solenoid axis, at a distance of $20 \mathrm{~mm}$ and $10 \mathrm{~mm}$ from central axis. The results are shown in Fig. 3. Only absolute values of field are shown in Fig. 3a because of the logarithmic scale. It is found that the perpendicular component $(\mathrm{X})$ is higher than the radial component $(\mathrm{Y})$ and parallel components $(\mathrm{Z})$, and the $\mathrm{X}$ component can be reduced by two orders of magnitude if a straight wire with reverse current is passed through the center of the solenoid. The $\mathrm{Y}$ and $\mathrm{Z}$ components remain unchanged, since the magnetic field produced by the straight wire wraps around the wire, which is shown here in the $\mathrm{X}$ direction only. The fluctuations of field value were also observed at very close to the solenoid and the period is consistent

\section{$\rightsquigarrow X \circ Y \Delta Z$}
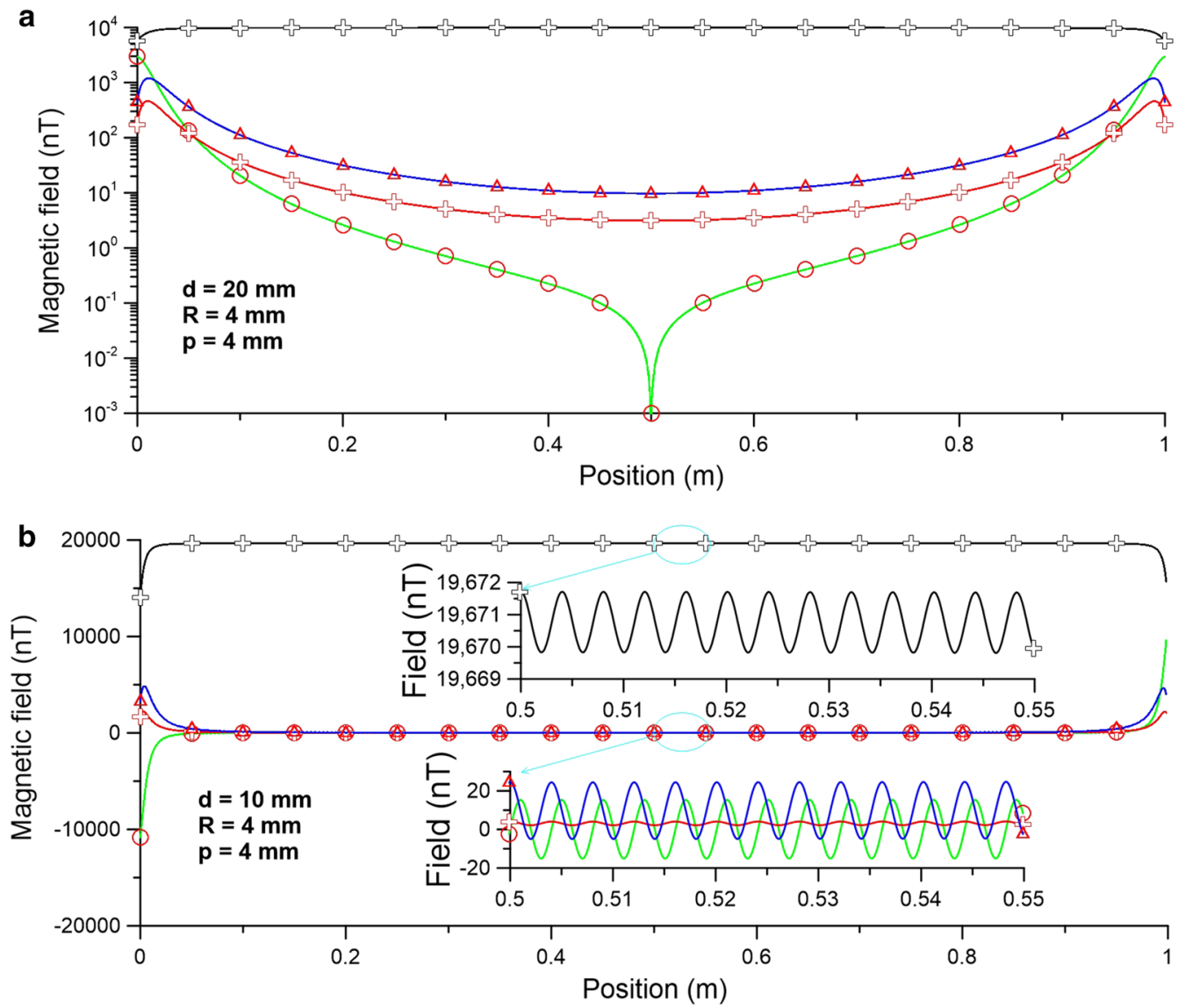

Fig. 3 Magnetic field simulations of single long solenoid at a $10 \mathrm{~mm}$ and $\mathbf{b} 20 \mathrm{~mm}$ from the central axis. The black symbol represents the result of conventional solenoid and the red symbol represents the result of a solenoid with a reverse straight wire at solenoid axis. Insets in $\mathbf{b}$ show detail measurements over the central 50-cm highlighting period nature of the field, which is caused by the solenoid pitch 
with the pitch (Fig. 3b). As the distance increases, the periodic fluctuation becomes insignificant (Hagel et al. 1994). The magnetic field distribution in other cases can be obtained by changing parameters of the solenoid, such as radius, pitch. It is useful to optimize the structure of heating wire before practical manufacture.

In fact, the whole heater group consists of a series of parallel or anti-parallel heating element solenoid and its configuration determined the magnetic field inside the furnace. We calculate the magnetic field distribution in the furnace. The heater composed of 12 conventional solenoids or new heating elements with opposite current direction between adjacent is simulated. Contour maps of different components are shown in Fig. 4. The parameters of each solenoid are the same as those used in Fig. 3, and the current is still set to $1 \mathrm{~A}$. X, Y and Z represent the magnetic field in horizontal, vertical and along the axis direction in the furnace, respectively. It can be seen that the magnetic field in the center of the furnace is extremely low for both configurations, but the low magnetic field area is considerably enlarged in the furnace with new heating elements. The magnetic field inside the solenoid is relatively complex, but does not affect the thermal demagnetization samples. Different configurations which are consistent with some practical applications can also be simulated. A large magnetic field may be produced by parallel connection of heating wire groups (Fig. 5). However, the magnetic field is still very low inside the furnace with same configuration using the new straight core solenoid.

\section{Measurement of solenoid magnetic field}

In order to verify the effectiveness and determine the magnetic field of the new heating element, the respective magnetic fields produced by the conventional solenoid heating wire and the new heating element were measured with a triaxial fluxgate magnetometer (APS520). One solenoid heating element with length of $1 \mathrm{~m}$ and diameter of $8 \mathrm{~mm}$ was placed inside a magnetically shielding cylinder with $1 \mathrm{~A} \mathrm{DC}$ current applied in the wire (Fig. 6a). The fluxgate sensor was placed to the side of solenoid at vertical distance of about $20 \mathrm{~mm}$ and moved along the long axis direction. The magnetic field at different positions was observed with the current on then off. In the same way, we measured the magnetic field of our new straight core solenoid heating element, which is composed of the same solenoid with a straight wire passing through it (Fig. 6b). The solenoid and the straight wire
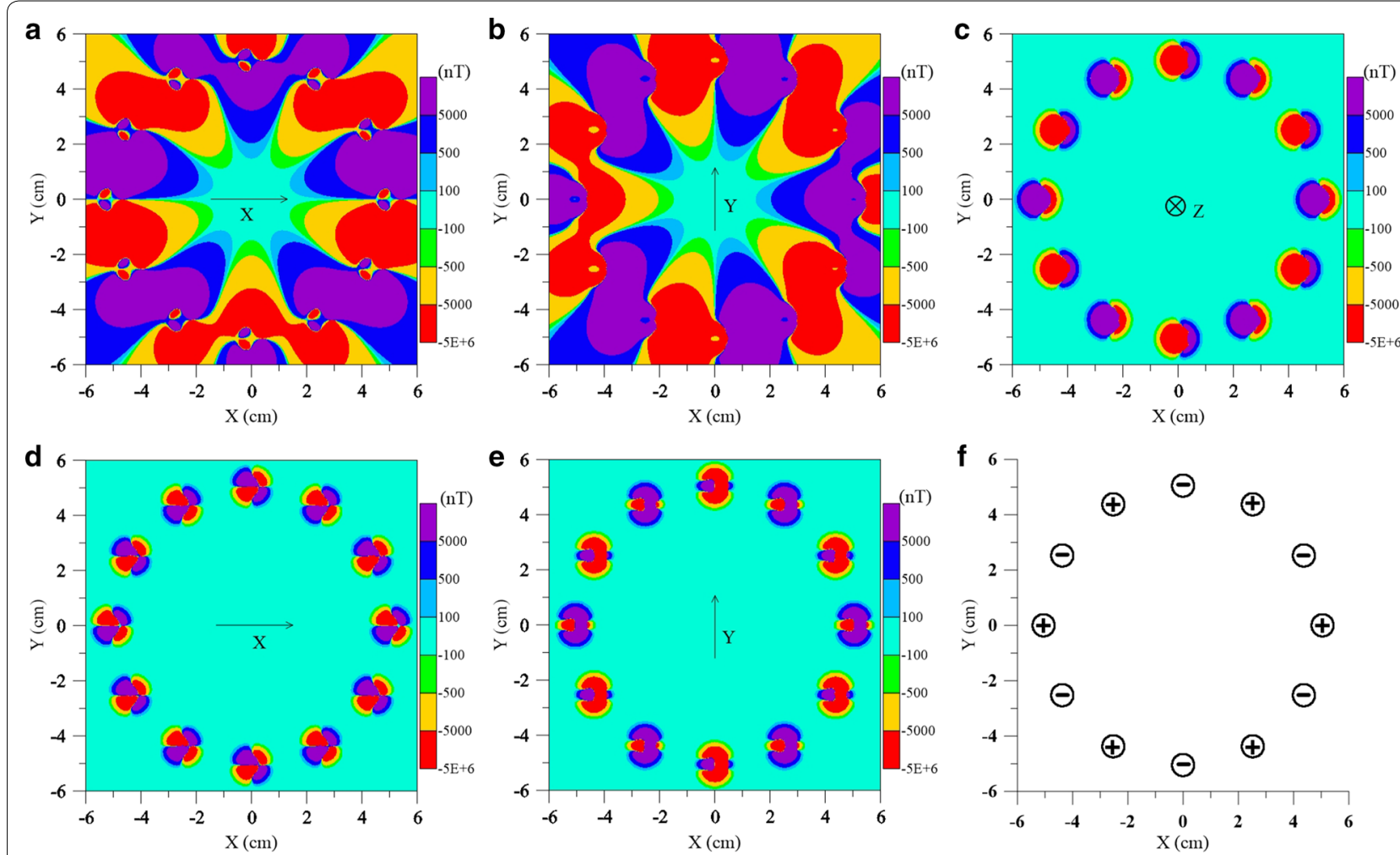

Fig. 4 Contour map of magnetic field distribution on different components in middle cross section of the furnace with composed of 12 conventional solenoids $(\mathbf{a}-\mathbf{c})$ and new heating elements $(\mathbf{d}, \mathbf{e}) . \mathbf{f}$ The position of the solenoids and the corresponding current direction in adjacent. Letter $X, Y, Z$ in the middle of the graph represents the direction of the magnetic field 

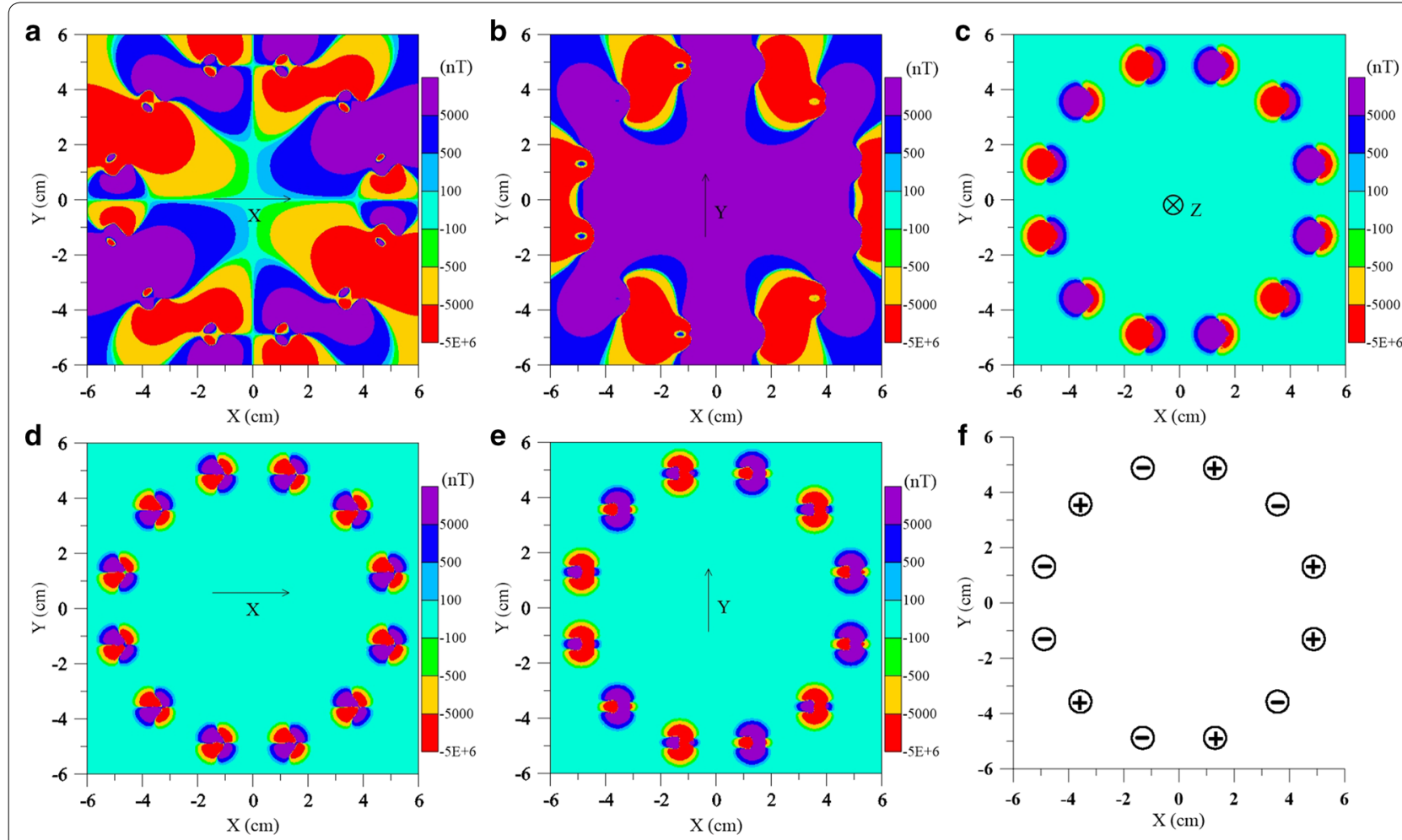

Fig. 5 Contour map of magnetic field distribution if the solenoids are wired such that the current flow is parallel. a-c The field distribution composed of 12 conventional solenoids, and $\mathbf{d}$, e the field distribution with new heating elements. $\mathbf{f}$ The position of the solenoids and the corresponding current direction in adjacent. Letter $X, Y, Z$ in the middle of the graph represents the direction of the magnetic field

were isolated by a ceramic sheath. The results are shown in Fig. 6c. The magnetic field of conventional solenoid is about $6000-7000 \mathrm{nT}$ and field direction is almost perpendicular to the long axis of solenoid and is consistent with the simulation, which is almost equivalent to that of an axial line current. The stray magnetic field of the straight core solenoid is much lower than the standard solenoid, with a total field intensity of 26-535 nT.

In our prototype, thermal demagnetizer adjacent elements are arranged in opposite directions (Fig. 7a). The magnetic field at different positions along the axis of the heating chamber were measured when a DC current of 1 $\mathrm{A}$ is applied to the heating wire. We measured the magnetic field four times at different vertical distances from the center axis. The peak magnetic field in the sample region is about $130 \mathrm{nT}$ (Fig. 7b). In order to verify the effect, we also arranged the conventional solenoids following the same structure, and the current of adjacent solenoids is opposite. It is found that the magnetic field in the center is relatively low (115-285 $\mathrm{nT}$ in sample zone), but gradually increases toward the edge of the furnace (Fig. 7c). However, if the wire connection is changed, parallel connection of two groups are adopted, the magnetic field will become higher and mainly in the vertical direction (Fig. 7d). The measured results are consistent with the numerical simulation.

\section{Degaussing the shield cylinder and the TD-PGL-100}

In order to shield the influence of external magnetic field, the chamber of thermal demagnetization furnace is usually installed in a cylindrical magnetic shield cylinder. The residual fields in sample zone typically vary from several $\mathrm{nT}$ to $150 \mathrm{nT}$ in different furnaces (Paterson et al. 2012), which is mainly determined by the remanent magnetization of magnetic materials within the furnace, especially the shields (Freake and Thorp 1971; Thiel et al. 2007). A lower residual field can be achieved by AF demagnetization of the shield cylinder. Early experiments found that the best shield demagnetization results were obtained by passing the $\mathrm{AC}$ current through conductors within the shield cylinders or by passing the current longitudinally through the shielding material itself (Herrmannsfeldt and Salsburg 1964). A circular magnetic field perpendicular to the central longitudinal axis will be produced in the cylindrical shield if a current conducting straight wire is passed though the 


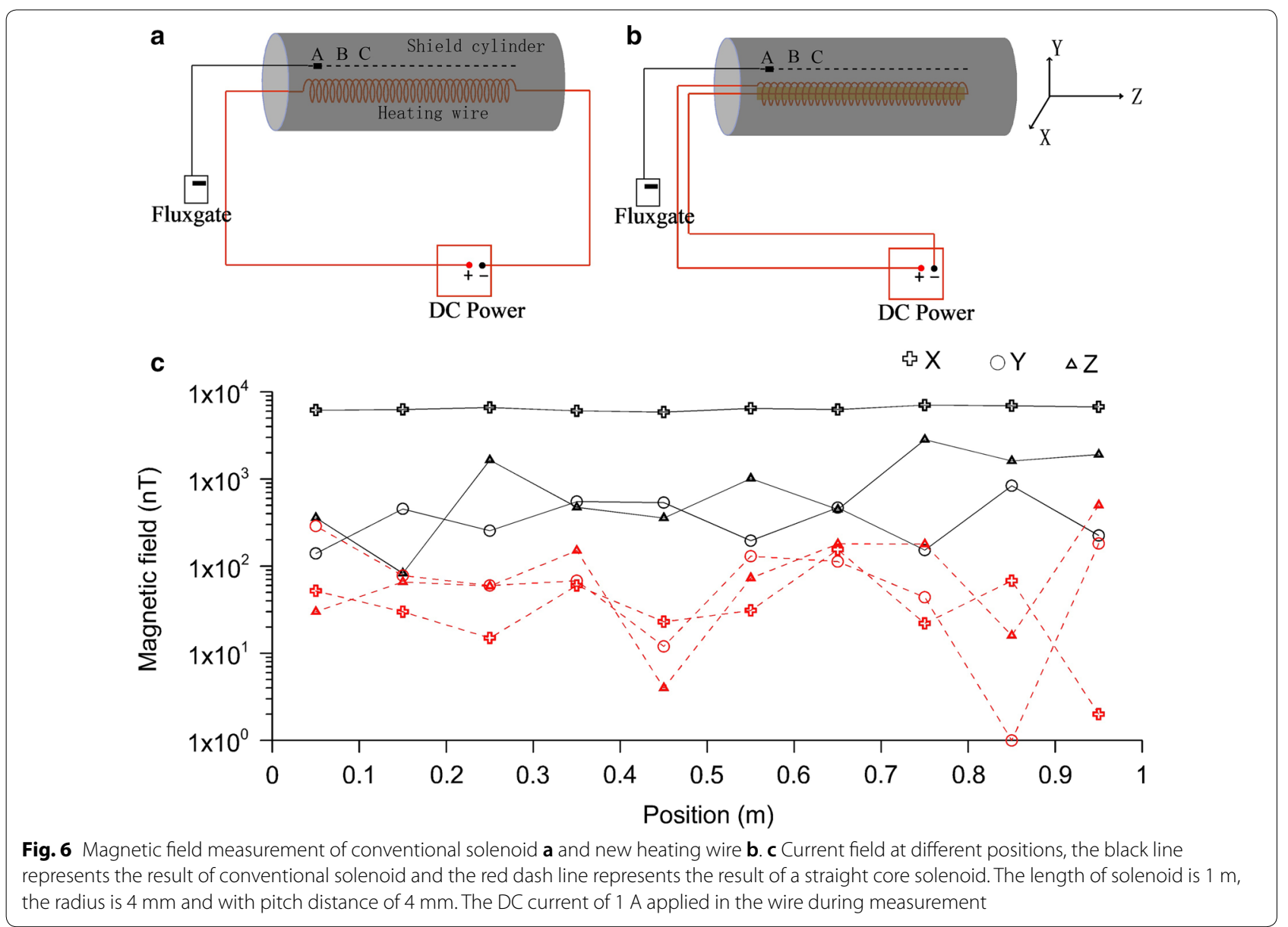

longitudinal center axis of the shield cylinder, however, this requires a large current to reach peak demagnetization. In practice, we use a total of eight $4 \mathrm{~mm}^{2}$ copper lines wound from inside to outside of the shield cylinder to form a large coil (Fig. 8a), and connected to a transformer with a twisted-pair cable. The transformer has separated primary and secondary windings which can be pulled apart. Separating the windings will generate a nonlinear attenuation of the alternating current in the coil which performs AF demagnetization of the shield cylinder. The residual magnetic field in the sample region can be as low as $1 \mathrm{nT}$ (Fig. 8b), which makes it possible to further reduce spurious fields during thermal demagnetization.

A new furnace named TD-PGL-100 had been built based on above-mentioned techniques. The furnace has a chamber of $120 \mathrm{~cm}$ length and $9 \mathrm{~cm}$ diameter, and the sample zone is designed as $60 \mathrm{~cm}$ in length, which allows up to 100 standard paleomagnetic specimens be treated together. Temperature gradient in the sample zone is within $10{ }^{\circ} \mathrm{C}$ of target temperature below $600{ }^{\circ} \mathrm{C}$ and $12{ }^{\circ} \mathrm{C}$ at $700{ }^{\circ} \mathrm{C}$. The maximum power consumption of the furnace is 4.0 KVA. Employing an adjustable voltage silicon-controlled rectifier over a solid-state relay allows the output power to be decreased as the temperature approaches the target point, which helps to avoid temperature overshoots. With careful tuning, the oven temperature has a $1{ }^{\circ} \mathrm{C}$ accuracy with a resolution of $0.1{ }^{\circ} \mathrm{C}$. As the examples of heating and cooling curves shown in Fig. 9, the temperature rises rapidly at the beginning of heating, and gradually approaches the target temperature after $\sim 30 \mathrm{~min}$ and then the temperature is maintained for a hold time to ensure the samples are thoroughly heated. The cooling fan can be turned on manually or automatically to cool the samples down. The temperature drops rapidly and slows when approaching room temperature. The heating and cooling data can be logged into USB memory automatically, which is essential for the thermal treatment and related experiments particularly for absolute paleointensity studies, where temperature reproducibility is important. 


\section{a}
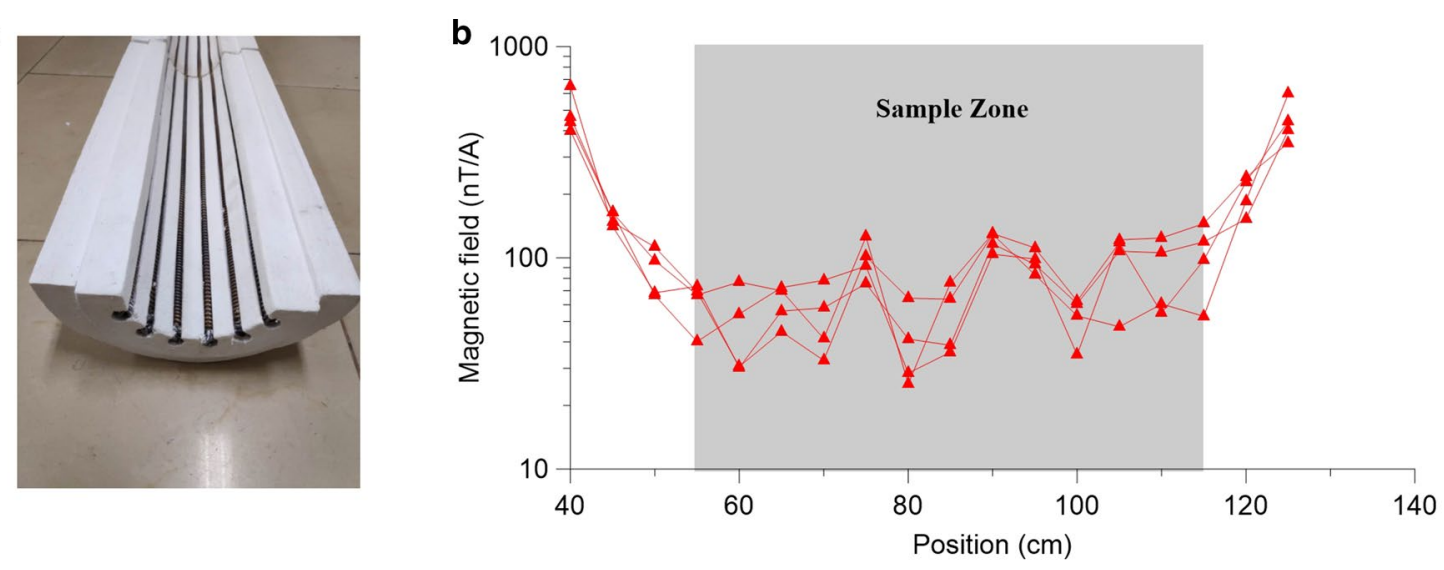

C
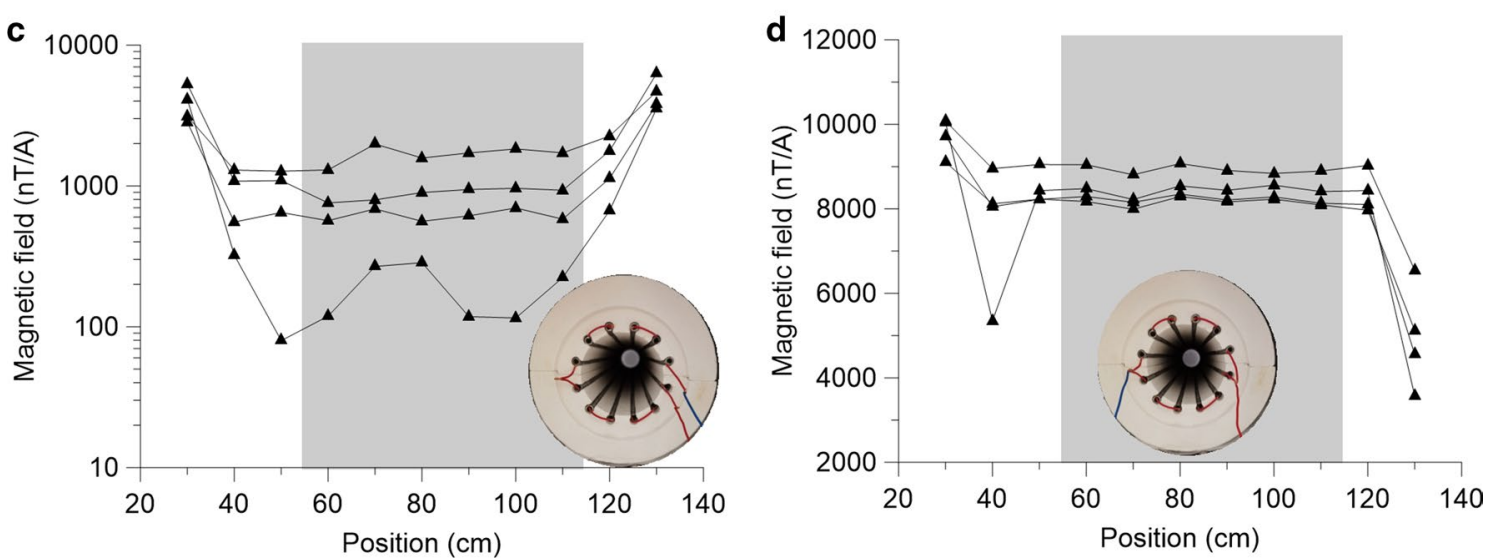

Fig. 7 a Photo of the new furnace chamber. $\mathbf{b}$ Current field (red triangles) with 1 A applied to the heating wire along longitude axis in the newly designed furnace (multiple curves represent different vertical distances from the central axis). c Current field with $1 \mathrm{~A}$ applied to the heating wire along longitude axis in conventional furnace, the current of adjacent solenoids is opposite. $\mathbf{d}$ Current field with $1 \mathrm{~A}$ applied to the heating wire along longitude axis in conventional furnace, currents of adjacent solenoids in each group are opposite, but two groups in parallel connect
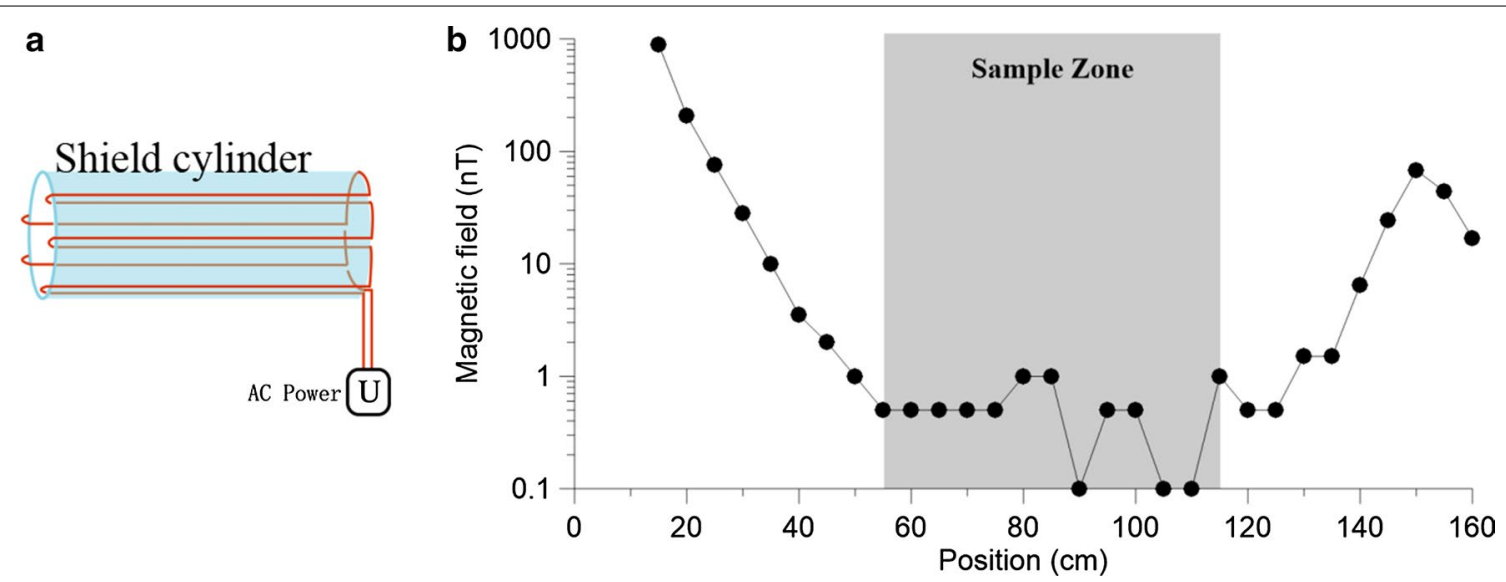

Fig. 8 a Toroidal degaussing coil embodying the shield cylinder. b Residual fields (black circles) along longitude axis in the newly designed furnace 


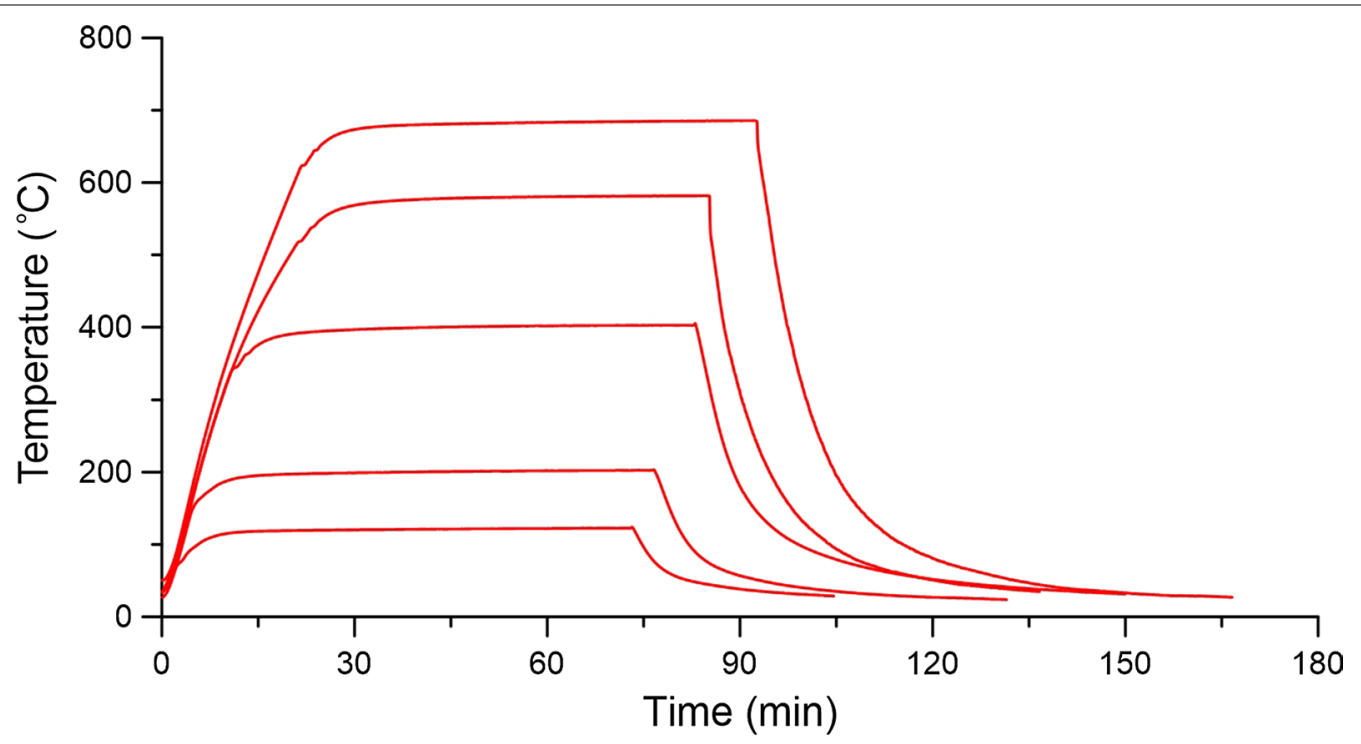

Fig. 9 Temperature curves during heating and cooling at different target temperatures in a thermal demagnetization experiment

\section{Examples of thermal demagnetization experiment}

In order to verify the effectiveness of the new furnace, thermal demagnetization experiments were carried out on 12 natural specimens and 8 synthetic specimens using TD-PGL-100. Nine sandstone specimens denoted as "B" were collected from Cenozoic strata in Yunnan, and three muddy limestone specimens denoted as "CM" were from Tibet. The main magnetic carrier mineral of sandstone specimen is hematite ( $\mathrm{Li}$ et al. 2017). They have only a single univectorial component decaying steadily toward high temperature. The muddy limestone specimens also contain hematite and have multi-component characteristics of different temperature ranges. Hematite specimens synthesized in the lab were chosen to avoid potential thermochemical changes during multiple heatings. The particles of hematite are cubic (Ozaki et al. 1986; Sugimoto et al. 1993) and with a broadly uniform size distribution with an average length and width of $570 \mathrm{~nm}$ and $545 \mathrm{~nm}$, respectively.

We have also tried to evaluate the influence of the background magnetic field. After progressive thermal demagnetization of TRM was carried out to identify the unblocking temperature spectrum of the synthetic hematite specimens, the specimens were heated to $700{ }^{\circ} \mathrm{C}$ for complete thermal demagnetization, then the progressive thermal demagnetization was repeated. Remanent directions and moments were measured with a cryogenic magnetometer system (2G Enterprises 755 ) installed in the magnetically shielded room with residual field $<300$ $n T$ at IGGCAS. Background noise is typically lower than $2 \times 10^{-12} \mathrm{Am}^{2}$, and the background moment of the sample tray was kept less than $5 \times 10^{-11} \mathrm{Am}^{2}$ during the measurements. All the experiments were completed in the paleomagnetic laboratory at the Institute of Geology and Geophysics, Chinese Academy of Sciences (IGGCAS).

The thermal demagnetization experiments of natural specimens show that good demagnetization results can be obtained using the new furnace. The representative experimental results are shown in Fig. 10. The remanence directions of some specimens do not change much after demagnetization at high temperature, when the remanence intensity is less than 10\% of the NRM intensity. The ChRM of high temperature can be successfully isolated for the specimens with multi-component characteristics. The magnetic moments of synthetic specimens during the repeated progressive thermal demagnetization are about $0.02-0.05 \%$ of the $30 \mu \mathrm{T}$ TRM (see detail in Additional file 1)). It confirms that the influence by undesirable magnetic fields from the furnace is very small.

\section{Discussion}

For comparison, Zheng et al. (2010a) investigated similar 1-A current field $(\sim 240 \mathrm{nT})$ for the commercially available Sogo Fine-TD. They also reported a 0.5-A current field for the ASC TD48 and Natsuhara as being 3600 and $1600 \mathrm{nT}$, respectively (equivalent to $1 \mathrm{~A}$ fields of 7200 and $3200 \mathrm{nT}$, respectively). We noticed that they obtained an abnormal field higher than $100 \mu \mathrm{T}$ at $0.3 \mathrm{~A}$ in the MMTD80 thermal demagnetizer, which may be produced by the applied field coil for the paleointensity experiment. Subsequently, a low field (48.4nT/A along the oven axis and less than 3nT/A at right angles in oven axis) was reported by Shaw (2010), and a relatively higher 

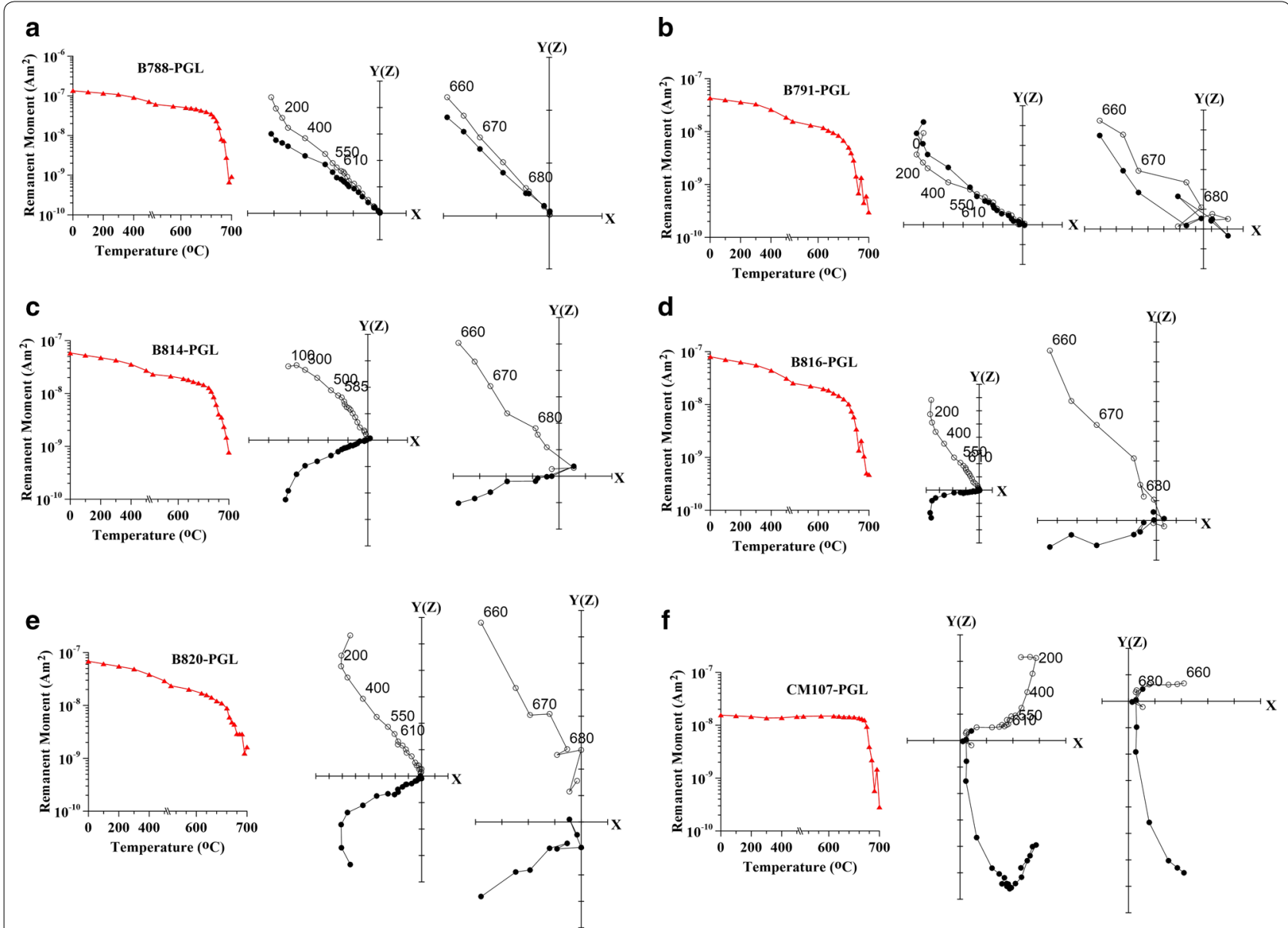

Fig. 10 Thermal decay curves and corresponding orthogonal plots of progressive thermal demagnetization of natural specimens. Solid (open) circles indicate projection on the horizontal (vertical) plane

field of $\sim 840 \mathrm{nT} / \mathrm{A}$ by Zheng et al. (2010b), respectively. Our simulation and experimental results show that the magnetic field inside the furnace using conventional solenoid is non-uniform. Although the heater configuration with conventional solenoids can also cancel out the magnetic field especially at the center, for effective cancellation of the fields generated in each solenoid, this design requires that opposing solenoids are perfectly antiparallel. Imperfect alignment results in small, but potentially significant AC fields when large currents are applied during heating (Zheng et al. 2010a, b; Shaw 2010). In contrast, the new design with straight core solenoid can reduce the dependence on symmetry of configuration, and can also obtain a large space of low magnetic field.

We use our new straight core solenoid heating element to build a new furnace named TD-PGL-100. Subsequently measurements in our later builds have peak current field of only $\sim 95$ nT/A. This new design, which holds up to 100 specimens, represents a 2-3 times reduction in AC fields compared to the eight-specimen Sogo
Fine-TD, and a 9 to 77 times reductions compared to other high-capacity demagnetizers. Yuan et al. (2020) investigated paleomagnetic behavior of red beds in the Sangdanlin section using the new furnace. The results can be reasonably compared with the previously published paleomagnetic results for the same section using the ASC TD48 by Yang et al. (2019). Clearly, excellent paleomagnetic directional data of high-temperature component $\left(650-680^{\circ} \mathrm{C}\right) \mathrm{can}$ be defined using the data from new furnace, while some remanence directions become erratic after thermal demagnetization at $620-660{ }^{\circ} \mathrm{C}$ using the ASC TD48. This comparison supports that the new thermal demagnetizing furnace has better performance.

It should be noted that the current field is an alternating magnetic field. In thermal demagnetization, the current field is more like the effect of AF demagnetization, and the way to cut off the heating current (e.g., abrupt on-off, or gradual ramping, etc.) may affect the demagnetization effect. However, the new design combined with the appropriate mode of AC supply has the 
potential to further lower the impact. Although our improved heating element can greatly reduce the AC current field, it cannot completely eliminate it. If lower AC magnetic fields are required, the only alternative would be to heat the specimens outside of the primary electrical heating element region. This could be achieved by heating the sample region by hot gas flow heated outside the sample region. This style of furnace can reduce AC current field to practically zero (Heller et al. 1970). Such gas flow furnace systems, however, are limited to heating only a small number of specimens. Our new TD-PGL-100 thermal demagnetizer with lower AC current field and super low residual magnetic fields is a reasonable choice for most paleomagnetic laboratories.

\section{Conclusions}

Here, we introduce a new heating element that is composed of a straight wire inserted into solenoid and connected in series at one end, a configuration we call a straight core solenoid. Such a configuration can drastically reduce the stray magnetic fields generated when a current is applied to the heating element. We also adopted a demagnetization procedure that can reduce the residual magnetic field in shield cylinder to less than $1 \mathrm{nT}$ in sample zone. The TD-PGL-100 built with those technologies allows the successful recovery of weak magnetizations blocked at high temperatures and has applications in recovering sedimentary magnetizations, records of geomagnetic polarity reversals, signals of the earliest geodynamo, as well as extraterrestrial magnetizations. One of this new thermal demagnetizers has been running normally for 3 years in the IGCCAS laboratory, and results demonstrate its excellent performance especially for these weakly magnetic natural specimens (Jiang et al. 2017; Yan et al. 2018).

\section{Supplementary information}

Supplementary information accompanies this paper at https://doi. org/10.1186/s40623-020-01304-0.

Additional file 1. Thermal demagnetization experiment of synthetic specimens.

\section{Abbreviations}

NRM: The natural remanent magnetization; AC: The alternating current; ChRM: The stable characteristic remanent magnetization; pTRM: Partial thermoremanent magnetization; AF: The alternating field; DRM: The detrital remanent magnetization.

\section{Acknowledgements}

We thank Jie Yuan and Dr Shihu Li for providing the natural samples for testing. We also thank Jeff Gee and three anonymous reviewers for reviewing the earlier version of the manuscript.

\section{Authors' contributions}

$\mathrm{HQ}$ : instrument development; experimental design; figures plotting; manuscript writing. XZ: instrument manufacture; key issues discussion; manuscript revising. SL: test of instrument. GP: key issues discussion; manuscript revising. ZJ: preparation of synthetic samples. SC: experimental test and data analysis. $J$ : key issues discussion. QL: proposing idea; framework design; manuscript revising. RZ: supervision of work and manuscript evaluation. All authors read and approved the final manuscript.

\section{Funding}

This work was supported by NSFC grants 41674073 and the Project of National Deep Exploration Technology and Experimental Research (Grant number: SinoProbe-09-02(201011079)). G.A.P. acknowledges funding from a NERC Independent Research Fellowship (NE/P017266/1).

\section{Availability of data and materials}

Not applicable.

Ethics approval and consent to participate

Not applicable.

\section{Consent for publication}

Not applicable.

\section{Competing interests}

The authors declare that they have no competing interests.

\section{Author details}

${ }^{1}$ State Key Laboratory of Lithospheric Evolution, Institute of Geology and Geophysics, Chinese Academy of Sciences, Beijing 100029, China. ${ }^{2}$ Research School of Earth Sciences, Australian National University, Canberra ACT 2601, Australia. ${ }^{3}$ Key Laboratory of Earth and Planetary Physics, Institute of Geology and Geophysics, Chinese Academy of Sciences, Beijing 100029, China.

${ }^{4}$ Department of Earth, Ocean and Ecological Sciences, University of Liverpool, Liverpool L69 7ZE, UK. ${ }^{5}$ Key Laboratory of Submarine Geosciences and Prospecting Techniques, Ministry of Education, and College of Marine Geosciences, Ocean University of China, 266100 Qingdao, People's Republic of China.

${ }^{6}$ Department of Marine Science and Engineering, Southern University of Science and Technology, Shenzhen 518055, China.

Received: 6 August 2020 Accepted: 23 October 2020

Published online: 04 November 2020

\section{References}

Budnik K, Machczynski W (2011) Modeling magnetic field in the vicinity of a single wire helix. Comput Appl Elect Eng 9:69-77

Chamalaun FH, Porath H (1968) A continuous thermal demagnetizer for rock magnetism. Pure Appl Geophys 70(1):105-109

Collinson DW (1975) Instruments and techniques in paleomagnetism and rock magnetism. Rev Geophys 13(5):659-686

Collinson DW (1983) Methods in rock magnetism and paleomagnetism: techniques and instrumentation. Chapman and Hall, London

Freake SM, Thorp TL (1971) Shielding of low magnetic fields with multiple cylindrical shells. Rev Sci Instrum 42:1411. https://doi. org/10.1063/1.1684894

Heller F, Scriba H, Weber M (1970) A furnace for magnetic investigations of rocks. Geophys J Int 21(5):531-534

Hagel R, Gong L, Unbehauer R (1994) On the magnetic field of an infinitely long helical line current. IEEE Trans Magn 30:80-84. https://doi. org/10.1109/20.272518

Herrmannsfeldt WB, Salsburg BL (1964) Demagnetization of magnetic shield in the presence of the earth's field. Rev Sci Instrum 35:906. https://doi. org/10.1063/1.1746861

Holm EJ, Verosub KL (1988) An analysis of the effects of thermal demagnetization on magnetic carriers. Geophys Res Lett 15:487-490

Irving E, Robertson WA, Stott PM, Tarling D, Ward MA (1961) Treatment of partially stable sedimentary rocks showing planar distribution of directions of magnetization. J Geophys Res 66:1927-1933. https://doi.org/10.1029/ JZ066i006p01927 
Jiang ZX, Liu QS, Dekkers MJ, Zhao X, Roberts AP, Yang ZY, Jin CS, Liu JX (2017) Remagnetization mechanisms in Triassic red beds from South China. Earth Planet Sci Lett 479:219-230. https://doi.org/10.1016/j. epsl.2017.09.019

Li S, Yang Z, Deng CL, He HY, Qin HF, Sun L (2017) Clockwise rotations recorded in redbeds from the Jinggu Basin of northwestern Indochina. Geol Soc Am Bull 129:1100-1122. https://doi.org/10.1130/b31637.1

Ozaki M, Suzuki H, Takahashi K, Matijevic E (1986) Reversible ordered agglomeration of hematite particles due to weak magnetic-interactions. J Colloid Interface Sci 113(1):76-80

Paterson GA, Biggin AJ, Yamamoto Y, Pan YX (2012) Towards the robust selection of Thellier-type paleointensity data: The influence of experimental noise. Geochem Geophys Geosyst 13:543. https://doi.org/10.1029/2012G C004046

Schmidt PW (1993) Paleomagnetic cleaning strategies. Phys Earth Planet Inter 76:169-178. https://doi.org/10.1016/0031-9201(93)90066-।

Sugimoto T, Sakata K, Muramatsu A (1993) Formation mechanism of monodisperse Pseudocubic [alpha]-Fe2O3 particles from condensed ferric hydroxide gel. J Colloid Interface Sci 159(2):372-382

Shaw J (2010) Comment on "A new high-precision furnace for paleomagnetic and paleointensity studies: minimizing magnetic noise generated by heater currents inside traditional thermal demagnetizers" by Zhong Zheng, Xixi Zhao, and Chorng-Shern Horng. Geochem Geophys Geosyst 11:1111. https://doi.org/10.1029/2010GC003211

Stephenson A (1983) Changes in direction of the remanence of rocks produced by stationary alternating field demagnetization. Geophys J R Astronom Soc 73:213-239. https://doi.org/10.1111/j.1365-246X.1983. tb03815.x

Tarduno JA, Cottrell RD, Davis WJ, Nimmo F, Bono RK (2015) A Hadean to Paleoarchean geodynamo recorded by single zircon crystals. Science 349(6247):521-524

Thellier E (1966) Methods and apparatus for alternating current and thermal demagnetization. In: Runcorn SK (ed) Methods and Techniques in Geophysics. Interscience, London, pp 205-249

Thiel F, Schnabel A, Knappe-Grüneberg S, Stollfuß D, Burghoff M (2007) Demagnetization of magnetically shielded rooms. Rev Sci Instrum 78:035106. https://doi.org/10.1063/1.2713433
Wang H, Weiss BP, Bai XN, Downey BG, Wang J, Wang J, Suavet C, Fu FF, Zucolotto ME (2017) Lifetime of the solar nebula constrained by meteorite paleomagnetism. Science 355:623-627

Wasilewski PJ (1969) Thermochemical remanent magnetization (TCRM) in Basaltic Rocks. J Geomagn Geoelectr 21(3):595-613

Weiss BP, Gattacceca J, Stanley S, Rochettte P, Christensen UR (2010) Paleomagnetic record of meteorites and early planetesimal Differentiation. Space Sci Rev 152:341-390. https://doi.org/10.1007/s11214-009-9580-z

Yan Y, Huang B, Zhang D, Charusiri P, Veeravinantanakul A (2018) Paleomagnetic study on the Permian rocks of the Indochina Block and its implications for paleogeographic configuration and northward drifting of Cathaysialand in the Paleo-Tethys. J Geophys Res 123:4523-4538. https:// doi.org/10.1029/2018JB015511

Yang T, Jin J, Bian W, Ma Y, Gao F, Peng W, Ding J, Wang S, Zhang S, Wu H, Li H, Yang Z (2019) Precollisional Latitude of the Northern Tethyan himalaya from the paleocene redbeds and its implication for greater India and the India-Asia collision. J Geophys Res 124:10777-10798

Yuan J, Yang ZY, Deng CL, Krijgsman W, Hu XM, Li SH, Shen ZS, Qin HF, An W, He HY, Ding L, Guo ZT, Zhu RX (2020) Rapid drift of the Tethyan Himalaya terrane before two-stage India-Asia collision. Natl Sci Rev. https://doi. org/10.1093/nsr/nwaa173

Zheng Z, Zhao X, Horng CS (2010a) A new high precision furnace for paleomagnetic and paleointensity studies: Minimizing magnetic noise generated by heater currents inside traditional thermal demagnetizers. Geochem Geophys Geosyst 11:408. https://doi.org/10.1029/2010GC0031 00

Zheng Z, Zhao X, Horng CS (2010b) Reply to comment by John Shaw on "A new high-precision furnace for paleomagnetic and paleointensity studies: Minimizing magnetic noise generated by heater currents inside traditional thermal demagnetizers. Geochem Geophys Geosyst 11:1112. https://doi.org/10.1029/2010GC003295

\section{Publisher's Note}

Springer Nature remains neutral with regard to jurisdictional claims in published maps and institutional affiliations.

\section{Submit your manuscript to a SpringerOpen ${ }^{\circ}$ journal and benefit from:}

- Convenient online submission

- Rigorous peer review

- Open access: articles freely available online

- High visibility within the field

- Retaining the copyright to your article

Submit your next manuscript at $\boldsymbol{\nabla}$ springeropen.com 